\title{
The Controllability of Monetary Aggregates in Pakistan
}

\author{
ANJUM SIDDIQUI and AHMAD WAHEED
}

\section{INTRODUCTION}

The introduction of new financial instruments ${ }^{1}$ and the consequent asset substitutability since the advent of financial deregulation in 1991 has been accompanied by volatility of the money multiplier and the monetary aggregates. While money demand studies exist [Khan (1980)], the modelling of the supply side of money and, in general, the impact of financial innovations on money multipliers and monetary aggregates has been largely ignored. ${ }^{2}$ In a recent study, Siddiqui and Waheed (1994a) found that during 1992-93 the narrow money multiplier fell and increased sharply, causing instability in M1. It was also observed that the broad money multiplier showed similar instability during the same period.

While financial innovations have been reflected in multiplier instability, inflation and monetary aggregates have also shown an upward trend. Since 1988-89 monetary assets (M2) have registered an increase of 137 percent with an accompanying inflation increase of 60 percent on average. This makes a strong case for controlling the growth of monetary assets in Pakistan.

The objective of the paper is to use a suggested monetary control procedure so as to reduce the variance of quarterly monetary growth. Section II suggests a monetary control procedure to track the targeted money supply. Section III assesses the predictive performance of the suggested control procedure by comparing the model simulations with targeted money. Section IV is the conclusion.

\section{A PROCEDURE FOR MONETARY CONTROL}

The literature suggests that via quantity theory, the intermediate monetary aggregate should be the one that has the strongest links with the GNP. Due to ease of monitoring, and assuming a stable demand for currency, the first response of a central

Anjum Siddiqui is Business Planning Adviser to Engro Chemical Pakistan Ltd., Karachi. Ahmad Waheed is Research Associate at the Applied Economics Research Centre, University of Karachi.

'Banks and money market dealers can now improve their profitability by indulging in repurchase of T-bills (REPO facility) to meet their liquidity needs. Hitherto, T-bills were earning a low fixed return of 6 percent determined by the SBP. The REPO facility was accompanied and made possible by the auction of T-bills, which allowed financial institutions to earn about twice the yield that they were earning
before the reforms.

${ }^{2}$ There are two earlier studies, Hamdani (1976) and Mangla and Ladenson (1978), but these studies suffer from the now well-known problem of non-stationary time series. Hence their estimated
coefficients and their predictive power is questionable. 
bank would be to target non-interest-bearing money (M1). ${ }^{3}$ However, since credit cards and other interest-earning deposits are used for expenditures, broad money suggests itself as a useful intermediate monetary target.

To conduct the experiment of devising a procedure for a better tracking of the targeted money, we first generate a series for targeted money. The SB.P can provide estimates of targeted money either through estimations from a macro-econometric model, an ARIMA model, or by simply pulling out ad hoc numbers from a hat. The choice of the method is immaterial for the determination of targeted money.

We assume as if the SBP generated its targeted money growth through an ARIMA process. The estimated model for target money growth is given in Appendix A. To track this targeted series, the SBP follows the multiplier approach to the determination of money supply. The multipliers, and hence the simulated adjusted base, and consequently the simulated money, are estimated using the following forward-looking estimation procedure.

(1) Using all available information till period $t$, a one-period-ahead forecast of the money multiplier is made for period $t+1$.

(2) Given this forecast and the level of desired M2 in period $t+1$, the amount of adjusted monetary base to support that money stock is determined, and the base is changed to achieve this new desired or targeted level. Thus, any deviation of the actual money stock from the targeted level is the result of a money multiplier forecast error.

(3) In period $t+1$, the forecast of the multiplier is re-calculated for $t+2$, taking into account the money multiplier information available in period $t+1$.

(4) Again in $t+l$, the adjusted base necessary to achieve the targeted money stock in $t+2$ is calculated. This procedure is followed each month to achieve the desired money stock. ${ }^{4}$ It is quite clear that the achievement of the targeted money stock objective crucially rests on accurate predictions of the money multiplier. Any discrepancies in meeting the targeted money are then attributed to errors in forecasting the money multiplier. ${ }^{5}$

${ }^{3}$ Siddiqui and Waheed (1994) have experimented with targeting MI and found that, by using their suggested monetary control procedure, the variance of actual quarterly narrow money was reduced.

${ }^{4}$ An alternative procedure is the multi-state Kalman filter (MSKF) method. Unlike the BoxJenkins procedure (1970), the MSKF technique tries to identify the nature of the shocks to the multiplier and uses this information in forecasting. In terms of forecasting performance, both the Box-Jenkins and the MSKF technique yield similar and good results in terms of tracking the peaks and troughs of the predicted multiplier series. However, by design, the MSKF technique is relatively more flexible. For an application of this procedure, see Hafer et al. (1983).

${ }^{5}$ One could argue that the time series behaviour of the multiplier would have been different had the State Bank actually followed the above targeting procedure. Two points can be made against this assertion. First, this critique can be levelled against all simulation experiments and it is not possible to determine the usefulness of this critique. Second, the critique is based on the assumption that the multiplier forecasts are rendered useless by the endogeneity of the base money during the period in which the multiplier is being estimated. Brunner and Meltzer (1983) have shown that these assertions are highly questionable. 
It needs mention that the above control procedure does not reduce the monthly variability in actual M2 growth. The objective is to achieve the announced monthly targets so as to reduce the variance of quarterly growth. If for any reason a target is missed in any particular month, then the simulated series would show a larger variability in the next month so as to zero in on the next month's target. Because the control procedure attempts to correct errors in money growth each month, it follows that the month-to-month variability in simulated growth could be large.

As pointed out above, looked at from the quarterly (or yearly) time horizon, the quarterly (or yearly) variability of the simulated series would be less than the monthly (quarterly) variability. This is due to the "smoothing" going on each month (quarter). ${ }^{6}$

\section{TRACKING TARGETED AND ACTUAL M2 GROWTH WITH SIMULATED M2}

Using the models of the money multiplier from Appendix C, we simulate $e x$ ante money growth for the period covering financial reforms, i.e., 1992 and 1993. Money growth is simulated by the control procedure discussed in Section II. Table 1 shows the consolidated results for monthly and quarterly data.

For the monthly models, the simulated level of M2 is on average tracking the targeted series quite closely. Nevertheless, some notable errors exist in a few months of each year. The largest discrepancies occur in March 1992 and August 1992, with targeted money exceeding the simulated levels by Rs 30.8 billion and Rs 22.7 billion respectively.

As expected, the monthly growth rates for simulated M2 are erratic under the proposed control procedure. This is seen by comparing the pattern of growth rates of the simulated with the actual M2. For the months of February and June in 1992, the actual M2 was showing positive growth rates while simulated money was declining. Similarly, for the months of February and April in 1993, actual M2 was showing negative growth rates while simulated money was increasing.

The results of tracking targeted money with simulated money are on average better for quarterly data. Table 1 shows that the simulated money is very closely tracking targeted money in 1993. However, in 1992 there are some discrepancies as seen in the first and third quarters. ${ }^{7}$

\footnotetext{
${ }^{6}$ The smoothing of monetary fluctuations has implications not only for inflation but also for real activity. To the degree that money is causally related with real GDP, the amplitude of the business cycle would be reduced. Thus, policy-makers would be able to minimise the output loss functions of the type given by Sargent and Wallace (1975) amongst others.

${ }^{7}$ An important reason for the simulated quarterly series not being able to track the targeted series closely is that the simulations are done for.an ex ante period, and that too a volatile period of regime change, from a regulated to a deregulated market. Hence, there are larger forecast errors in predicting our targeted series. Consequently, the simulated series incorporates this error.
} 
Table 1

Simulating M2, Using Estimated Money Multipliers

\begin{tabular}{rccccc}
\hline Period & $\begin{array}{c}\text { Targeted } \\
\text { M2 }\end{array}$ & $\begin{array}{c}\text { Actual } \\
\text { Multiplier }\end{array}$ & $\begin{array}{c}\text { Forecast } \\
\text { Multiplier }\end{array}$ & $\begin{array}{c}\text { Adjusted } \\
\text { Base }\end{array}$ & $\begin{array}{c}\text { Simulated } \\
\text { M2 }\end{array}$ \\
\hline & \multicolumn{5}{c}{ Monthly Model } \\
I/1992 & 412.0 & 1.1958 & 1.1809 & 348.9 & 417.2 \\
$2 / 1992$ & 417.0 & 1.1899 & 1.1904 & 350.3 & 416.8 \\
$3 / 1992$ & 416.2 & 1.0944 & 1.1815 & 352.2 & 385.4 \\
$4 / 1992$ & 397.9 & 1.1725 & 1.1189 & 355.6 & 417.0 \\
$5 / 1992$ & 416.9 & 1.1628 & 1.1359 & 367.0 & 426.8 \\
$6 / 1992$ & 437.4 & 1.1288 & 1.1688 & 374.2 & 422.4 \\
$7 / 1992$ & 446.1 & 1.1591 & 1.1218 & 397.7 & 461.0 \\
$8 / 1992$ & 451.6 & 1.2256 & 1.1518 & 392.1 & 480.6 \\
$9 / 1992$ & 478.5 & 1.1823 & 1.1994 & 399.0 & 471.7 \\
$10 / 1992$ & 476.0 & 1.1855 & 1.1951 & 398.3 & 472.1 \\
$11 / 1992$ & 478.2 & 1.1927 & 1.1823 & 404.5 & 482.4 \\
$12 / 1992$ & 502.4 & 1.1850 & 1.2032 & 417.5 & 494.7 \\
$1 / 1993$ & 516.9 & 1.1794 & 1.1891 & 434.7 & 512.7 \\
$2 / 1993$ & 541.0 & 1.1832 & 1.1762 & 459.9 & 544.2 \\
$3 / 1993$ & 540.4 & 1.1862 & 1.1640 & 464.2 & 550.7 \\
$4 / 1993$ & 551.1 & 1.1831 & 1.1808 & 466.7 & 552.2 \\
$5 / 1993$ & 545.8 & 1.1966 & 1.1772 & 463.6 & 554.8 \\
$6 / 1993$ & 552.7 & 1.1993 & 1.1910 & 464.0 & 556.5 \\
$7 / 1993$ & 562.2 & 1.1421 & 1.1827 & 475.4 & 543.0 \\
$8 / 1993$ & 561.4 & 1.1246 & 1.1718 & 479.1 & 538.7 \\
$9 / 1993$ & 553.8 & 1.1699 & 1.1263 & 491.7 & 575.2 \\
$10 / 1993$ & 570.8 & 1.1457 & 1.1508 & 469.0 & 568.3 \\
$11 / 1993$ & 576.0 & 1.1478 & 1.1529 & 499.6 & 573.4 \\
$12 / 1993$ & 596.3 & 1.1545 & 1.1585 & 514.7 & 594.2 \\
& & & & & \\
I/1992 & 403.7 & 1.0944 & 1.1549 & 349.5 & 382.6 \\
II/1992 & 419.4 & 1.1288 & 1.0937 & 383.5 & 432.9 \\
III/1992 & 419.2 & 1.1823 & 1.1195 & 374.5 & 442.8 \\
IV/1992 & 487.9 & 1.1850 & 1.1960 & 407.9 & 483.4 \\
I/1993 & 500.8 & 1.1938 & 1.1764 & 425.7 & 500.3 \\
II/1993 & 561.4 & 1.1993 & 1.1875 & 472.8 & 561.5 \\
IV/1993 & 582.1 & 1.1699 & 1.1857 & 490.9 & 574.3 \\
& 612.1 & 1.1736 & 1.1487 & 519.3 & 609.5 \\
\hline
\end{tabular}


Recall that reducing the monthly variability of money growth was not the objective. The aim was to achieve a reduction in the quarterly growth rate variability, which has been achieved to some degree.

Table 2 shows that in 1993 the variance of the quarterly simulated M2 is 3.86 as compared to 7.93 in the actual M2 growth. In 1993, however, the expected reduction in the variance of the simulated series was not achieved. But, over the whole two-year period, a reduction of 27.25 percent in the standard deviation of simulated M2 is achieved.

Finally, in Table 3, we also observe that the simulated series tracks the growth rate of targeted M2 quite closely, in spite of the methodology of measuring targeted money.

The divergence between the targeted and the simulated money is on average 2.5 percent over the two-year period. For 1992 the simulated series exceeds the targeted series by 5 percent. But in 1993, the difference between the two series is only 0.4 percent.

Table 2

Variability of Actual and Simulated $M_{2}$ Growth'

\begin{tabular}{lccccc}
\hline \multirow{2}{*}{ Period } & \multicolumn{2}{c}{ Monthly } & & \multicolumn{2}{c}{ Quarterly } \\
\cline { 2 - 3 } 1992 & Actual & Simulated & & Actual & Simulated \\
\hline 1993 & 2.83 & 4.26 & & 7.93 & 3.86 \\
\hline & 1.75 & 2.75 & & 2.64 & 3.83 \\
\hline
\end{tabular}

'Variability measured by standard deviation of growth rates.

. Table 3

Comparison of Targeted and Simulated $M_{2}$ Growth Rates

Period

Desired $\mathrm{M}_{2}$ Growth

Simulated $\mathrm{M}_{2}$ Growth 


\section{CONCLUSION}

The study estimated the M2 money multipliers and used them to predict the targeted money growth series for monthly and quarterly data. The suggested monetary control procedure was successful in reducing the variability of the quarterly growth rate of the stock of $M 2$. The simulated money growth series tracks the targeted money growth quite well, deviating only by 2.5 percent.

A useful policy recommendation is that while short-term inflation may have non-monetary causes, double-digit and rising long-term inflation in Pakistan can largely be stemmed by controlling the growth of monetary assets while monitoring other instruments as well. Further research needs to be conducted to examine the behaviour of various components of M2, i.e., the currency-deposit and time-deposit ratios. 
Appendix A Monthly Data

Estimated Models of Targeted M2 and the M2 Money-multiplier

$\begin{array}{llc}(1+0.35 \mathrm{~B})(1-\mathrm{B})\left(1-\mathrm{B}^{12}\right) \mathrm{mm}_{2} & = & \left(1+0.91 \mathrm{~B}^{12}\right) t \\ (6.38) & (46.67) \\ (1+0.28 \mathrm{~B})(1-\mathrm{B})\left(1-\mathrm{B}^{12}\right) \mathrm{M}_{2}= & \left(1+0.87 \mathrm{~B}^{12}\right) \\ (5.29) & & (31.91)\end{array}$

\section{Quarterly Data}

$$
\begin{array}{ccc}
\left(1-0.21 \mathrm{~B}^{2}\right)(1-\mathrm{B})\left(1-\mathrm{B}^{4}\right) \mathrm{mm}_{2} & = & \left(1+0.86 \mathrm{~B}^{4}\right) t \\
(2.27) & & (20.17) \\
\left(1+0.57 \mathrm{~B}^{2}\right)(1-\mathrm{B})\left(1-\mathrm{B}^{4}\right) \mathrm{M}_{2} & = & \left(1+0.54 \mathrm{~B}^{4}\right) t \\
(4.57) & (3.09) \\
\hline
\end{array}
$$

Notes: The absolute values of $t$ statistics are in parentheses.

$\mathrm{M}_{2}$ is the targeted money supply and $\mathrm{mm}_{2}$ is the money-multiplier.

\begin{tabular}{cccc}
\multicolumn{4}{c}{ Ex-ante Forecasts of the M2 Money-multiplier } \\
\hline $\begin{array}{c}\text { Summary } \\
\text { Statistics }\end{array}$ & $01 / 1992-12 / 1993$ & $01 / 1992-12 / 1992$ & $01 / 1993-12 / 1993$ \\
\hline Monthly Model & & & \\
RMSE & 0.03463 & 0.03880 & 0.02508 \\
MAE & 0.02609 & 0.03029 & 0.01815 \\
MAPE & 2.25046 & 2.61296 & 1.65237 \\
U & 0.01479 & 0.01656 & 0.01072 \\
B & 0.00245 & 0.00776 & 0.00032 \\
V & 0.01646 & 0.02017 & 0.04270 \\
C & 0.98109 & 0.97205 & 0.95698 \\
Quarterly Model & & & \\
RMSE & 0.03477 & 0.04730 & 0.01343 \\
MAE & 0.02745 & 0.04234 & 0.01256 \\
MAPE & 2.38888 & 3.71842 & 1.05933 \\
U & 0.01493 & 0.02066 & 0.00568 \\
B & 0.01561 & 0.01956 & 0.00568 \\
V & 0.00024 & 0.00009 & 0.35545 \\
C & 0.098415 & 0.98035 & 0.62071 \\
\hline
\end{tabular}

Note: RMSE is the root-mean squared error; MAE is the mean-absolute error; MAPE mean-absolute percentage error; $U$ is the Theil inequality coefficient; $B, V$, and $C$ represent the amount of forecast error due to bias, variation, and co-variation, respectively, between the actual and the forecast series. 


\section{REFERENCES}

Box, P. E. George, and M. G. Jenkins (1970) Time Series Analysis, Forecasting and Control. Holden-Day, Inc.

Brunner, K., and A. H. Meltzer (1983) Strategies and Tactics for Monetary Control.

Carnegie Rochester Conference Series 18: 59-104.

Hafer, R. W., Scott, E. Hein, and C. J. M. Kool (1983) Forecasting the Money Multiplier: Implication for Money Stock Control and Economic Activity. Federal Reserve Bank of St. Louis, Review April: 22-33.

Hamdani, Mazahir H. (1976) Money Multiplier as a Determinant of Money Supply: The Case of Pakistan. The Pakistan Development Review 15:2 211-217.

Khan, Ashfaque H. (1980) The Demand for Money in Pakistan: Some Further Results. The Pakistan Development Review 19:1 25-50.

Mangla, I. U., and Mark Ladenson (1978) Short-run Forecast of Money Stock in Pakistan. The Pakistan Development Review 17:2 169-190.

Sargent, T. J., and N. Wallace (1975) Rational Expectations, the Optimal Monetary Instrument and the Optimal Money Supply Rule. Journal of Political Economy 83: 241-255.

Siddiqui, Anjum, and Ahmad Waheed (1994) Tracking M1 via the Money Multiplier in Pakistan. Manuscript. Karachi: Applied Economics Research Centre, University of Karachi.

Siddiqui, Anjum, and Ahmad Waheed (1994a) Forecasting the Money Multiplier with Component and Aggregate Models. Manuscript. Karachi: Applied Economics Research Centre, University of Karachi. 


\section{Comments}

This paper by Anjum Siddiqui and Ahmad Waheed comes at a very opportune time, given the massive deregulation taking place in the monetary and financial sectors of Pakistan's economy, amidst dangers that loosening of government controls on these sectors may lead to instability and inflation. Indeed, the paper seems to be motivated precisely by the apparent plausibility of such dangers. This plausibility is evident from the very high inflation figure for the last five or so reform years quoted by the authors. The plausibility is also quite clear from the various stop-gap measures announced by the government from time to time which go against its financial deregulation policy stance but which, nevertheless, are designed to curb monetary expansion and inflation. The very recent decision by the State Bank not to allow any further expansion in credit to the private sector for the remainder of this year, in spite of announcing earlier an increase in the credit deposit ratios, bears testimony to the fact that the central bank remains seriously concerned with the controllability of monetary aggregates.

To begin with, I have two general points to make. First, inflation, at least partly, may be the result of non-monetary factors, and therefore exercising some kind of monetary control may not necessarily eliminate it. As is well known, the current policy of financial deregulation is being undertaken under the general umbrella of the structural adjustment and stabilisation programmes. As is also well-known, these programmes involve direct measures that may increase the rate of inflation at least in the short run. These programmes may involve reduction or elimination of agricultural subsidies and increasing utility prices progressively to the market level. In addition, trade reforms and especially devaluation, both by increasing the domestic price level and the price of imported items, particularly raw materials, may contribute significantly to inflationary pressures. Therefore, the relative contribution of monetary and non-monetary factors to inflation in the last few years may be a subject of debate. Incidentally, coming from Cambridge, England, I do not in any case entirely subscribe to the monetarist contention that inflation is always and everywhere a monetary phenomenon!

Secondly, it seems to me to be premature to be more than reasonably concerned about the inflationary impact of financial deregulation. Financial reforms are still very much in their infancy and stability may gradually return with the maturation of these reforms. For instance, one of the stated objectives of the State Bank in developing the secondary securities market is that once developed, it will help curb monetary expansion by encouraging more asset holdings, thereby reducing the demand for money. Financial reforms may, therefore, entail some automatic 
checks to curb the growth rate of money. The authors of the present paper themselves estimate that the standard deviation measuring the variability of the quarterly series of M2 fell from 7.93 in 1992 to 2.64 in 1993, i.e., in just one year. Of course, this decline may purely be a chance phenomenon, given that one year is too short a period for the reforms to start taking effect. However, what emerges from this discussion is that it is probably a bit too soon to establish any kind of hypothesis regarding the variability of money following financial deregulation.

A more specific point concerns the methodology used in the paper. I would agree that so far as establishing the mechanism of the control procedure is concerned, it makes no difference how the target level of money supply is decided, which in this case is done through ARIMA modelling. The authors then forecast money multipliers, again using an ARIMA model, and make adjustments in the money base to achieve the target level of money supply. Money supply is then simulated on the basis of the adjusted money base and the authors conclude that the overall variability of the simulated series is less than the variability of the actual M2 series. However, as the figures for the money base on which the simulations depend are adjusted to achieve the target level of money supply, different target levels of money supply estimated from different models would necessitate different adjustments in the money base, and consequently the variation in the simulated money series in each case will be different. The variation in the different cases could be higher or lower than the variation in the actual money series. The results of the paper seen in this context are, therefore, dependent on the way in which the target money supply is modelled.

A final point on methodology is over the use of ARIMA or other time series models during a period of structural change in the financial and other sectors of Pakistan's economy. Time series models of the ARIMA-type do not incorporate structural features of an economy and, therefore, their reliability in terms of predictions and forecasts, which is contingent upon the continuation of existing trends into the future, is brought into question in the current state of change and flux in Pakistan's economy. This is one reason why the forecasts of the money multiplier reported in the paper are not terribly accurate. Even so, the simulated money supply seems to be tracking the targeted money supply reasonably well.

The authors' conclusion, based on their empirical analysis that "the suggested monetary control procedure was successful in reducing the variability of...M2", also needs some qualification. It is clear from the figures reported by the authors that the variability of the simulated money supply is less than that of the actual money supply for only one of the two reported years. For 1993, the variability of the simulated money supply is actually 45 percent higher than the actual money supply. However, by the authors' own admission, the objective of the control procedure outlined in the paper is to attain the targeted level of money supply and not to reduce the variation in the actual money supply. And it is only in this special sense that the paper addresses 
the issue of the controllability of monetary aggregates. The target levels of money supply and their variation, on the other hand, would be influenced by a mix of fiscal and monetary factors, including the government's borrowing requirements, the private sector's credit allocations, as well as policies of financial reform like eliminating credit ceilings, increased financial intermediation, and the development of a secondary market for securities. The controllability of money in this general sense would necessitate a prudent fiscal policy and the appropriate timing and sequencing of financial deregulation and reform.

Trinity College,

Safdar Parvez

University of Cambridge,

England. 